\title{
Contraception for adolescents: a growing need of today
}

\section{Rita Mittal*}

Department of Obstetrics \& Gynecology, Kamla Nehru State Hospital-IGMC, Shimla, Himachal Pradesh, India

Received: 17 January 2015

Accepted: 16 February 2015

\author{
*Correspondence: \\ Dr. Rita Mittal, \\ E-mail: mittaldrrita@gmail.com
}

Copyright: () the author(s), publisher and licensee Medip Academy. This is an open-access article distributed under the terms of the Creative Commons Attribution Non-Commercial License, which permits unrestricted non-commercial use, distribution, and reproduction in any medium, provided the original work is properly cited.

\begin{abstract}
The future of adolescent contraception requires the collaboration between providers, patients and sometimes their parents. Trends show that percentage of those with premarital sexual experience and adolescent pregnancy outside marriage in India are also on the rise making the situation worse and requiring urgent attention from policies and programmes. Teenage pregnancy prevention is a priority because of the implications for the patients as well as for the society as a whole. The ability to provide non-discriminatory, confidential, accessible care and our role in the education and guidance of our patients are likely to determine the future of this generation of teens.
\end{abstract}

Keywords: Adolescent, Contraception, Sexual intercourse

\section{INTRODUCTION}

Adolescence is the transition phase from childhood to adulthood. This is the time when the young people start experiencing sexual feelings and many start developing sexual relationships also. Early age at first intercourse is associated with unprotected sex increasing the risk of teenage pregnancy and Sexually Transmitted Infections (STI). ${ }^{1}$

Both these outcomes, teenage pregnancy and STI, are key public and health issues in adolescents.

That is why there is an urgent need to address this problem.

\section{DISCUSSION}

\section{Magnitude of problem}

About $30 \%$ of India's population is in the age group of 10-19 years. It is estimated that there are about 331 million adolescents in India. ${ }^{2}$ They represent a resource for the future whose potential can either be wasted or nurtured in a positive manner. Sexual and reproductive ill health is one of the major causes of morbidity and mortality in young people. ${ }^{3}$

The 2007 youth risk behaviour surveillance system, which tracks different health risk behaviours among high school students, including sexual behaviours, surveyed more than 14000 students from every state and the districts of Columbia. Important findings of the survey included the following:

1. $47.8 \%$ of the students reported ever having had sexual intercourse.

2. $7.1 \%$ of students reported having had sex before the age of 13 years.

3. $14.9 \%$ of students reported having had sex with four or more sexual partners.

4. $35 \%$ of students reported being currently sexually active, defined as having had sexual intercourse in the last 3 months.

5. $61.5 \%$ of sexually active students reported that they or their partner had used a condom during the last sex. 
These findings reinforce the importance of addressing contraceptive needs as this is a global phenomenon. ${ }^{4}$

Preventive visits are a great venue for discussing contraception even before the initiation of sexual activity. The American College of Obstetricians and Gynaecologists (ACOG) has recently published recommendations for the first visit with the gynaecologist between the ages of 13-15 years. ${ }^{5}$ The time spent with their provider allows adolescents the opportunity to identify risk factors and challenges that can be overcome before the actual problem arises.

\section{Barriers}

There are many problems or barriers for the adolescents to avail various facilities.

1. In a conservative society like India, the reproductive and sexual health related issues are taboo for discussion. Young people are hindered from actively seeking counsel for their needs.

2. Young people tend to use contraceptives that can be easily available with minimum embarrassment. ${ }^{1}$

3. They try to maintain confidentiality and use contraceptives that are available over the counter without prescription. ${ }^{1}$

4. Many teens perceive pelvic examination to be a barrier for accessing contraceptive services; therefore, the physical examination may be deferred if judged appropriate by the provider. ${ }^{5}$

5. They have usually inaccurate and incomplete knowledge about the sexual activity and most of the parents are hesitant to discuss such matters openly with their kids.

6. Teenagers usually get involved in first sexual act without planning.

7. There is misconception in many teenagers that they will not suffer from any problem and various problems are mainly limited to married women.

8. Family planning is influenced by social, religious and political forces from outside the medical community. Women's health care physicians must counsel and prescribe contraception despite challenges such as changing trends, frequent confusion and ignorance, but the advice must be based on the scientific evidence. Even in certain industrialized countries with more advanced contraception technologies, women especially teenagers are denied easy access to family planning services because of religious and political issues rather than medical reason. ${ }^{6}$

9. Lack of awareness - Ever use of contraception among adolescents is very low in India; only $13.4 \%$ use any method including traditional methods of contraception. When it comes to modern methods, only $8.2 \%$ of adolescents have ever used contraception. This is a dismal situation and tells us about their awareness, control on their reproductive health, potential health problems and also effect on their fertility. Current use is still low; the use of any method is $8 \%$ and use of modern method is only 4.7\%. Above all there is paucity of Adolescent Friendly Health Services (AFHS). ${ }^{7}$

While sex may be unplanned, contraceptive use can be planned. An effective means of reducing future complications is to ensure that sexually active adolescents must use contraceptives consistently and correctly.

\section{Action required}

The need is to look at how young people can be helped to understand not only the immediate consequences of risky sexual behaviour but also future consequences as this is a strong and direct predictor of health problems in adulthood. Unfortunately, most of the clinical evidence on contraceptive use comes from studies of older women. Clinical contraceptive studies should include more young people so that adolescent specific outcomes can be evaluated.

\section{Options available}

Various options that can be made available to adolescents are as follows:

1. Abstinence - Although abstinence is the most effective means of birth control, the lack of other contraception education has caused controversy and disagreement with the efforts of specialty societies. During first part of the decade, much emphasis was laid upon this as a method of birth control, but it is a well-known fact that this is not practically possible. ${ }^{8}$ The choice to remain or return to abstinence may be a difficult one for some adolescents.

2. Barrier methods - Barrier methods include such devices as male condoms, female condoms, cervical caps diaphragms and spermicidal gels etc. Though effective, their use is not consistent. The need for application before each act decreases their use by decreasing the spontaneity of the act.

The male condom is the most commonly used barrier method as it is cheap, easily available, easily disposable and additional protection from STI. Still they are not widely used because of personal beliefs and injudicious planning.

Female condoms have never achieved much popularity because of its cost, limited availability and cumbersome use. ${ }^{9}$ 
3. Combined OCPs - The combined pill is the most commonly used method in this group with the usage rate reaching up to $50 \%$ because it is safe, predictable, regular and pain free menses, convenient, efficient and privacy can be maintained. A wide range of options are available and all the brands are almost equally effective and any one can be used conveniently. Because the incidence and severity of side effects increase with age and smoking, the overall safety provided by OCPs in adolescents without history of thromboembolic disease this can be safely used and is not coitus dependent. $^{10}$

Unfortunately, despite the wide use of OCPs, adolescents have failure rates as high as $15 \%$ in the first year of use because of missed pill. Such cases may need more motivation and can be advised quick start method.

4. Other combined contraceptive methods - The contraceptive transdermal patch is also used by some adolescents, the failure rates and side effects are similar as in adult population. $21 \%$ experienced a patch coming off completely and $32 \%$ experienced a patch peeling partially in a corner. ${ }^{11}$

The vaginal contraceptive ring is another approved method, but it has to be worn throughout the month which makes it an unpopular choice.

The monthly injectable combination contraceptive that combines MPA $25 \mathrm{mg}$ and $5 \mathrm{mg}$ of estradiol cypionate is also one of the options.

5. Progestin only methods - The progestin only pill has been shown similar efficacy to OCPs. They have short half-life, so strict time compliance is necessary which leads to high failure rate. Moreover, there is high incidence of irregular bleeding.

DMPA is a common contraceptive used by adolescent population because of the minimal intervention on the part of patient to achieve compliance. Weight gain and irregular bleeding may be bothersome side effects in few subjects.

6. Emergency contraception - The use of nonabortifacient hormonal medication within 72 hours of unprotected sexual intercourse is very important component of contraceptive counselling in adolescents. The use of single dose of $150 \mathrm{mcgm}$ is quite efficacious and reduces the risk of pregnancy from $8 \%$ to $1-2 \%$. Every adult as well as every adolescent should have knowledge of this method and its proper use.

Funding: No funding sources

Conflict of interest: None declared

Ethical approval: Not required

\section{REFERENCES}

1. French RS, Cowan FM. Contraception for adolescents: spectra. Best Pract Res Clin Obstet Gynaecol. 2009 Apr;23(2):233-47.

2. New Delhi Office of the Registrar General. Census of India, 2001. Available at: http://www.censusindia.net/.

3. World Health Organization. The second decade: improving adolescent health and development. In: WHO, eds. Programme Brochure. Geneva: WHO, Department Child and Adolescent Health and Development; 1998.

4. Centers for Disease Control and Prevention. Youth risk behaviour surveillance - United States 2007. MMWR Surveil Summ. 2008;57(4):1-131.

5. American College of Obstetricians and Gynecologists. The initial reproductive health visit. ACOG Committee Opinion No.335. Obstet Gynecol. 2006;107:745-7.

6. William F. Rayburn. Obstetric and gynecologic emergencies. Obstet Gynecol Clin N Am. 2007;34:xvii-iii.

7. Adolescent Fertility and Contraception in India. Implications for reproductive health, 2005. Available at: http://paa2005.princeton.edu/papers/50236.

8. Kohler PK, Manhart LE, Lafferty WE. Abstinence only and comprehensive sex education and the initiation of sexual activity and teen pregnancy. J Adolesc Health. 2008;42:344-51.

9. Anderson FD, Hait HA. A multicentre, randomized study of an extended cycle oral contraceptive. Contraception. 2003;68:89-96.

10. Rimsza ME. Counseling the adolescent about contraception. Pediatr Rev. 2003;24:162-70.

11. Harel Z, Riggs S, Vaz R, Flanagan P, Dunn K, Harel D. Adolescents' experience with the combined estrogen and progestin transdermal contraceptive method Ortho Evra. J Pediatr Adolesc Gynecol. 2005;18:85-90.

DOI: $10.5455 / 2320-1770$. ijrcog20150401

Cite this article as: Mittal R. Contraception for adolescents: a growing need of today. Int J Reprod Contracept Obstet Gynecol 2015;4:292-4. 